\title{
Г.Г.Семкина
}

(Омский государственный университет им. Ф.М.Достоевского)

\section{О СЛОЖНОВСТАВНЫХ ПРЕДЛОЖЕНИЯХ КАК ОСОБОМ ТИПЕ СЛОЖНЫХ ПРЕДЛОЖЕНИЙ.}

В работе обосновывается необходимость выделения сложновставных предложений в качестве четвертого типа сложных предложений, наряду со сложносочиненными, сложноподчиненными и бессоюзными.

Предложения с вставными предикативными конструкциями традиционно рассматриваются либо как один из видов сложноподчиненных предложений [Ilysh 1971: 304; Кобрина 1999: 466; Бархударов 1973: 417; Blokh 2000: 319], либо в рамках простого (или осложненного) предложения [Валгина 2000: 251; Скобликова 1979: 227; Сиротинина 2003: 108; Гак 2004 : 732].

Такие трактовки данных предложений представляются не вполне адекватными, так как, в отличие от простых и осложненных предложений, они содержат две и более эксплицитно и полно выраженные предикативные линии, a в отличие от сложноподчиненных предложений, могут использовать различные (не только подчинительные) средства связи, и, главное, принципиально отличаются от них по семантике и коммуникативному назначению.

В частности, наиболее распространенным типом связи вставного предложения с включающим его основным предложением является бессоюзие (соположение), которое в течение долгого времени рассматривалось как «отсутствие грамматической связи» [см., например, Сиритинина 2003, Адмони 1973, Учебный 2005], однако в современном синтаксисе закономерно выделяется как один из основных структурно- 
семантических типов синтаксических связей [Гак 2004: 510-511; Лингвистический 1990: 74; Черемисина 1987: 96; Руднев 1968: 254].

Обычно отмечается, что соположение является способом выражения недифференцированной связи. При этом вставные предложения, бессоюзно соединенные с включающим предложением, могут передавать крайне разнообразную семантику. Это может быть персуазивность: I shall be punished for it now, I suppose, by being drowned in my own tears (L.K.); контактоустановление: Because I'm not myself, уои see (L.K.); Stop this moment, I tell you! (S.К.); пояснение, комментарии: He went back to the park (the make-out couple was gone, but the winos were still there, stinking the place up) and changed his English grade to a B (S.K.); самоуточнение: There is there was - a kind of "old boy network" in Brazil and Paraguay and Santo Domingo (S.K.).

Менее распространенным типом связи вставного предложения с включающим является сочинительная связь: Nothing was to be done that he did not do himself; though I am sure (and I do not speak it to be thanked, therefore say nothing about it) your uncle would most readily have settled the whole. [A.P.P.]

Еще одним средством синтаксической связи является подчинительная связь вставного предложения с включающим предложением. Большинство вставных предложений в этом случае носят авторизационный, контактоустанавливающий, ссылочный характер и присоединяются союзом as, as far as, if: Anyway, as the old barrelhouse song says, My God, how the money rolled in (S.K.); Perhaps, as you say, I was once a Nazi (S.K.); I never saw him again, nor, as far as I know, did anyone else who was sitting at our table last night (S.K.); But, as the man himself had observed, he was an American boy (S.K.). Подчинительными средствами присоединяются и акцентирующие по семантике предложения: Todd had some power over him, and, what's more important, he knew the truth (S.K.). Следует отметить, что подчинительные 
конструкции перечисленных семантических типов близки к фразеологизмам по уровню устойчивости средств выражения и использованию в них ограниченного круга лексических единиц (это большей частью глаголы речи и умственной деятельности). Этим данные конструкции отличаются от пояснительных, комментирующих, которые неограниченно широки по содержанию информации, и подчинительная связь в них выражена разнообразными союзами и союзными словами: Will you be very angry with me, my dear Lizzy, if I take this opportunity of saying (what I was never bold enough to say before) how much I like him? (A.P.P.); We made Berry (who was, in truth, nothing loath) order up I don't know how much more claret (F.B.); Mr. Crump, under pretence of going to the cellar (where he said he had some cases of the finest champagne in Europe), called Dick, the boy, to him... (M.W.)

Как можно заметить, помимо формально-грамматических сочинительных и подчинительных средств связи (союзов и союзных слов), а также соположения (при бессоюзии), предложения содержат и лексические средства связи, в частности, многообразные повторы и местоимения.

Важно, что несмотря на обычные для сложных предложений грамматические и лексические способы соединения, сложные предложения со вставными предикативными конструкциями не являются подтипами сложносочиненных, сложноподчиненных и бессоюзных предложений, поскольку существенно отличаются от них по семантике - ни в одном из этих типов предложений придаточные не передают вышеупомянутые значения персуазивности, авторизации, контактоустановления, ссылки, пояснения, комментария, самоуточнения, то есть, обобщая, дополнительной объективной или субъективной информации. Они образуют свой особый тип сложных предложений, которые можно назвать сложновставными, (Л.Л.Иофик предлагала термин «соотнесенные предикативные конструкции» [Структурный 1972]), поскольку по своей семантической 
функции и коммуникативному предназначению они занимают уникальное место в системе сложных предложений. Именно эти полипредикативные единицы создают относительную возможность для преодоления пространственно-временной линейности речи. Учитывая, что человеческая мысль способна схватить сразу несколько направлений развития событий, то и речь стремится к одновременной передаче этих нескольких планов содержания. На это в языке направлены некоторые грамматические категории, лексические элементы, синтаксические конструкции, среди которых предложениям со вставками отводится существенная роль. А.Ф.Прияткина отмечала, что высказывания со вставками характеризуются «семантико-синтаксической двуплановостью» [Прияткина 1990: 160], «об информативной двуплановости повествования» при использовании вставок говорили Г.Н.Акимова [Акимова 1990: 65] и Н.С.Валгина [Валгина 2000: 253]. Такие предложения максимально сближают различные содержательные слои, делая речь многоуровневой, многоплановой, причем степень проявления этого качества у сложновставных предложений на несколько порядков выше, чем у других сложных предложений. При этом, они сохраняют всю полноту предикативных линий, обеспечивая возможность представления нескольких временных, модальных и персональных значений в предельно спрессованном режиме.

Однако функциональное отличие сложновставных предложений от других сложных предложений заключается еще в том, что сложновставные предложения изначально ранжируют информацию для слушающего или читающего. Оформление одной или нескольких предикативных линий именно в виде вставной конструкции сразу позволяет адресату воспринимать ее содержание как дополнительное, сопутствующее, но ассоциативно важное для говорящего. Другие типы сложных предложений такой функции не имеют. 
Эта особая функция вставочных конструкций подтверждается несколькими исследованиями, проводимыми с позиций актуального членения. В частности, Е.А.Фенова отмечает, что вставные предложения «произносятся в низком участке диапазона, с уменьшенной громкостью, в убыстренном темпе и на письме оформляются в виде скобок или тире, вводя в основной текст новую или относительно независимую мысль, прерывая в нем, как правило, тесные синтаксические связи» [Фенова 1983: 84]. Е.А.Фенова подчеркивает, что вставные предложения (по терминологии Е.А.Феновой «истинные вставки») «обычно создают в высказывании многоступенчатое актуальное членение, так как внесение в текст новой мысли приводит к образованию в высказывании дополнительных рематических центров» [Фенова 1983: 85]. К подобной точке зрения приходят Е.П.Артеменко и С.А.Гостеева, отмечая, что «особая коммуникативная значимость вставочных конструкций... достигается благодаря их двойной актуализации - и как самостоятельных синтагм в соответствующих конструкциях, и как частей с акцетированным содержанием в составе предложений» [Артеменко 1985: 46].

Отметим, что коммуникативная значимость вставных конструкций может значительно усиливаться в сатирических и юмористических текстах, где автор намеренно помещает наиболее важную часть информации во вставной конструкции ради юмористического эффекта, основанного как раз на противоречии средства, которым представлена информация, и самой информации.

Таким образом, учитывая, что предложения, включающие вставные предикативные конструкции, содержат не менее двух полноценно выраженных предикативных линий (следовательно, в структурном отношении полностью соответствует определению сложного предложения), используют любые формально-грамматические и лексические средства связи, характерные для разных (а не какого-то одного) типов сложных 
предложений, имеют специфическое коммуникативное предназначение и выражают уникальную семантику, их следует рассматривать как четвертый вид сложных предложений (наряду со сложносочиненными, сложноподчиненными и бессоюзными) и называть сложновставными предложениями.

\section{Литература}

1. Адмони В.Г. Синтаксис современного немецкого языка. - Л., 1973.

2. Акимова Г.Н. Новое в синтаксисе современного русского языка. - М., 1990.

3. Артеменко Е.П., Гостеева С.А. Вставные конструкции в структурном и коммуникативном аспектах // Синтаксис русского предложения. Межвузовский сборник научных трудов. - Воронеж, 1985.

4. Бархударов Л.С., Штелинг Д.А. Грамматика английского языка. - М., 1973.

5. Валгина Н.С. Синтаксис современного русского языка. - М. 2000.

6. Гак В.Г. Теоретическая грамматика французского языка. - М. 2004.

7. Кобрина Н.А., Корнеева Е.А., Оссовская М.И., Гузеева К.А. Грамматика английского языка. Морфология. Синтаксис. - СПб., 1999.

8. Лингвистический энциклопедический словарь./ Ред. В.Н.Ярцева. - М., 1990.

9. Прияткина А.Ф. Русский язык: Синтаксис осложненного предложения. - М., 1990.

10.Руднев А.Г. Синтаксис современного русского языка. - М. 1968.

11.Сиротинина О.Б. Лекции по синтаксису русского языка. - М., 2003.

12.Словарь лингвистических терминов. / Редакция О.С.Ахманова. - М., 2004. 
13.Скобликова В.С. Современный русский язык. Синтаксис простого предложения. - М., 1979.

14.Структурный синтаксис английского языка. / Ред. Иофик Л.Л. - Л., 1972

15.Фенова Е.А. Роль вводных и вставных конструкций в организации функциональной перспективы высказывания // Вестник МГУ, серия 9, Филология, 1983, № 5.

16.Учебный словарь лингвистических терминов/ Ред. Л.А.Брусенская, Г.Ф.Гарилова, Н.В.Малычева. - Ростов-на-Дону, 2005.

17.Черемисина М.И. Очерки по теории сложного предложения. Новосибирск, 1987.

18.Blokh M.Y. A Course in Theoretical English Grammar. - M., 2000.

19.Ilysh B.A. The Structure of Modern English. - Л., 1971.

\section{Источники примеров}

L.C. - Lewis Carrol. Alice in Wonderland. M., 1999.

S.K. - Stephen King. Different Seasons. - N.Y.: New American Library.

A.P.P. - Austen Y. Pride and Prejudice. - London: Penguin Books, 1994.

F.B. - Fitz-Boodle G. Mr and Mrs Frank Berry. - London: Penguin Books, 1990.

M.W. - Fitz-Boodle G. Men’s wives. - London: Penguin Books, 1990. 